\title{
Reintroduction of patients suffering from repetitive strain injury in the Job Market: pilot-project preliminary data of the first phase
}

\author{
*Centro de Referência em Saúde do Trabalhador \\ **Núcleo de Investigação em Trabalho e Saúde da Secretaria de Estado da Saúde de São Paulo
}

Repetitive Strain Injuries (RSI) are increasingly important ocuppational hazard in Brazil, leading to considerable absence from work. To date, there are no aditional data however, data from workers' health reference centres in various states show that the prevalence of RSI is vey significant.

Workers from many different professional categories and ocupations have appeared suffering from the symtoms of RSI; among them, assembly-line workers, key-board workers, cashiers, bank workers, clerks, packing workers, telephone service operators, telemarketing operators and machine operators.

The main aim of this pilot research project was to investigate the ways unemployed workers registered as suffering from RSI reenter to job market. Workers from a multinational company responsible for assembling car radio and tape recorders were studied. This company is based in São Paulo and Employs 5.000 people. The majority of them are women.

Two main lines of investigation are to be followed. Firstly attempts have been made to identify the factors which prevented all those workers who have been made reduntant as RSI suffers from reentering the job market. Secondly a group of 50 ex-workers and RSI suffers will be focused on to identify in more detail the problems faced.
In 1987 the company issued only 31 Reports of Accidents at Work due to RSI. However in the years 1988 to 1992 the company issued 813 such reports.

As a result of this high incidence of RSI the company is now being sued.

Using this total of 844 Reports of Accidents at we Work have mailed a questionnaire to all whose addresses were available, 722 in total. Individuals were asked to give opinions about their attempts to find new jobs.

To date we have received 230 questionnaires (30,9\%), a high percentage, considering that people in Brazil are not used to answering questions by mail. However, we have not considered these replies representative because of the many factors that may have infuenced people to reply.

Of the 230 replies, 177 said they have not worked for the company anymore (54,3 said they left the company in 1992).

Among people who left the company, only 18 answered that nowadays they work for another company and $72,2 \%$ of them have been in a new jof only since 1993 (15 said that they are registered and 14 said that they do not do what they would like to).

The 18 people work in different categories, for example, 
business $(16,7 \%)$, clothes industry $(11,1 \%)$, hospital / Health Service $(16,7 \%)$, computer assembly $(5,6 \%)$, plastic / chemical industry $(11,2 \%)$, eletrochemical industry $(5,6 \%)$, services $(22,2 \%)$. textile industry $(5,6 \%)$ and food processing $(5,6 \%)$.

The specific jobs carried out by these people within the above categories include clerk $(5,6 \%)$, secretary $(5,6 \%)$, shop salesman $(5,6 \%)$, cashier $(5,6 \%)$, machine operator $(11,2 \%)$, assembly-line worker $(5,6 \%)$, nurse auxiliary $(5,6 \%)$, student monitor $(16,7 \%)$, seamstress $(5,6 \%)$, stock taker $(5,6 \%)$, eletronic auxiliary $(5,6 \%)$, trade agent $(5,6 \%)$, electrocardiogram operator $(5,6 \%)$ teacher $(5,6 \%)$ and packing worker $(5,6 \%)$.

Of the 177 people who do not work for the company anymore; 159 are still unimployed. The reasons given for this unemployement were: problems in upper limbs (paresthesia, pain, numbness)(84), no physical conditions to follow the work rythm in the companies (41), bad work reference (27\%), nobody wants to hire ex-worker from that company (23), too old for the job market (13), children (12), treatment (10), dificulty of a limited person to reenter the job maket (5), lack of experience in another job (3), sueing the Social Security (2), pregnancy (2), no job as assembli-line worker (1), not prepared psychologically speaking (1), not skilled to do a lighter job (1), dedication to home and study (1), did not know why was refused in many companies (4).
The jobs looked for the 177 workers no longer working for the company were: company without any specification (36), assembly-line worker (33), telephone operator (33), maid/cleaner (15), general helper (14), shop salesman (13), seamstress (12), informal job at home (6), cashier (5), chef (5), quality inspector (4), machine operator (3), textile operator (3), packing worker (3), teacher (3), student monitor (2), street market salesman (2), public service worker (2), selfemployed (1), hairdresser (1), driver (1), television extra (1), security agent (1), not looked for a new job (22).

A preliminary analysis of the data above show that the majority of people who left the company are still unemployed. Physical limitations produced directly or indireccty by RSI have being many difficulty, Most of the jopbs looked for demand repetitive movements of upper limbs and many of these jobs are associated with the occurecce of musculosketal injuries.

The first phase has given us a basis to prepare an interview protocol wich will be applied to 50 workers still unemployed. The objectivew or the second phase is a deeper analysis of the factors which will make it easyd pr difficult for these workers to reenter the job market and an evaluation of the social, family, physical, psycological functioning and the health perception. 